\title{
Perceptions and Acceptance of Levonorgestrel Implants among Family Planning Clients within greater Banjul Area, The Gambia
}

Isatou Dampha $^{1^{*}}$, Momodou Jasseh ${ }^{2}$ and Jainaba Sey-Sawo ${ }^{1}$

${ }^{1}$ University of The Gambia, MDI Road, Kanifing P.O. Box 3031, Serrekunda, The Gambia

${ }^{2}$ Medical Research Council, The Gambia Unit, Fajara, The Gambia, INDEPTH Network, Accra, Ghana

\section{Abstract}

A better understanding of women's perception of levonorgestrel implants has the potential to help women and their partners freely choose the number and spacing of their children and thus, increase contraceptive prevalence. The contraceptive prevalence rate is very low in the Gambia; only 8 per cent of the women of reproductive age use modern methods of family planning and 1 per cent using traditional methods and an implant utilization rate of $3.9 \%$. Therefore, the purpose of the study is centered on exploring the perceptions and acceptance level of Levonorgestrel Implants among family planning (FP) clients in Western Health Region One (WHR, 1). The perception and acceptance of implants among users is not well documented in the Gambia despite established knowledge of availability at little or no cost in most health facilities. A phenomenological qualitative study design was employed and twelve women were purposively selected from two hospitals to serve as participants. Focus group discussions were used as data collection method among six women per discussion. Qualitative data analysis method used for the study was the Editing Analysis Style where, the data were interpreted in search of meaningful segments and units. The data were analyzed using themes and categorizing the responses of the participants under each theme with verbatim quotes used wherever necessary. Sociodemographic findings revealed that majority of the women were between the ages of 30-39 (SD \pm 5.35 ) ranging from 25 to 45 years with a mean age of 32.75 years. More than half of the study participants had between $1-4$ children $(n=7,58.33)$, with a mean parity of 3.75 ( $S D \pm 2.48)$. Almost all of them were Muslims ( $\mathrm{n}=11,91.66 \%)$. All of them received some form of education with the highest level being secondary (Conventional) $(n=6,50 \%)$. Majority were housewives $(n=6,50 \%)$, married $(n=11,91.66 \%)$. The findings showed that six themes emerged from both Focus Group Discussions where the majority of the respondents gave similar answers. The themes that were reported on were; efficacy, service provider's attitude, husband/spousal approval, undesired effects, myths and misconceptions, and satisfaction. In conclusion, the use of Implants for family planning depends on clients' perceptions. Therefore, understanding client's perceptions on implants would help to improve prevalence, thus reducing unintended pregnancies, induced abortions, short birth intervals, fertility rates and maternal mortality and morbidity in the country.

\section{Background/Introduction}

A better understanding of perceptions of Levonorgestrel Implants has the potential to help women and their partners freely choose the number and spacing of their children and thus increase contraceptive prevalence. Levonorgestrel Implants are a hormonal contraceptive method and consist of small, thin, flexible plastic rods, each about the size of a matchstick, that release a progestin hormone into the body. The rods are inserted just under the skin of a woman's upper, inner arm by a nurse or midwife [1]. Globally, implant acceptance is on the increase. However, worldwide use of implants is low; among married women between the ages of 15 and 49 years, 53\% use a modern method of contraception, but only $0.3 \%$ use implants [2].

In sub-Saharan Africa, a growing number of women and sexually active adolescents are using family planning and many are choosing contraceptive implants. While implants account for just 7\% of all contraceptive methods used in the region, interest in implants has risen sharply in less than a decade [3]. Empirical evidence showed that implant contraceptives are highly effective and well tolerated. Similarly, implants are proven to be safe, effective and reversible contraceptive options [4,5]. In Malawi, Kamara, Rodriguez, ChorweSungani, and Chimwaza, found that the perceptions of couples on the Jadelle Implants centred around mode of action of Jadelle; knowledge about effectiveness and efficacy of Jadelle among men and women;

\section{Publication History:}

Received: July 18, 2018

Accepted: September 03, 2018

Published: September 05, 2018

\section{Keywords:}

Perceptions, Acceptance, Levonorgestrel Implants, Family Planning Clients, The Gambia and role played by men regarding use of Jadelle [6].

Furthermore, since 1975, family planning services have been free of charge and available in all public health sectors in The Gambia. According to The Gambia Demographic and Health Survey, the contraceptive prevalence is very low, that only $9 \%$ of currently married women use a contraceptive method of any kind, $8 \%$ use a modern method and Implant utilization rate is 3.9\% [7]. Anyawu and Alida revealed that implant was the second most commonly used long acting and reversible contraception (LARC) method (43.3\%) among study participants in the Gambia [8]. There is limited data in sources of information about Jadelle; information given to Jadelle users by providers; benefits of Jadelle; challenges associated with The Gambia on perception and acceptance on implant despite established knowledge of availability at little or no cost in most health

*Corresponding Author: Mrs. Isatou Dampha , University of The Gambia, MDI Road, Kanifing P.O. Box 3031, Serrekunda, The Gambia, Tel: +2203650148; E-mail: idampha@utg.edu.gm

Citation: Dampha I, Jasseh M, Sey-Sawo J (2018) Perceptions and Acceptance of Levonorgestrel implants among Family Planning Clients within greater Banjul Area, The Gambia. Int J Nurs Clin Pract 5: 293. doi: https://doi.org/10.15344/23944978/2018/293

Copyright: (C) 2018 Dampha et al. This is an open-access article distributed under the terms of the Creative Commons Attribution License, which permits unrestricted use, distribution, and reproduction in any medium, provided the original author and source are credited. 
Citation: Dampha I, Jasseh M, Sey-Sawo J (2018) Perceptions and Acceptance of Levonorgestrel implants among Family Planning Clients within greater Banjul Area, The Gambia. Int J Nurs Clin Pract 5: 293. doi: https://doi.org/10.15344/2394-4978/2018/293

Page 2 of 7

facilities. Therefore, it is in light of the above that the focus of the research is centered on exploring the perceptions and acceptance level of Levonorgestrel Implants among family planning (FP) clients in Western Health Region One (WHR 1), The Gambia.

\section{Statement of the problem}

Family planning services have been provided in the Gambia since the late 1960s, even though the Government did not adopt an explicit population policy until 1979. Subsequently, a national population policy was included in the National Health Programme that was formulated in 1994. The overall objectives of the family planning programme are to reduce the number of abortions and maternal deaths and to improve maternal and child nutrition, education and the family economy in general. Contraceptives are available in the private sector through pharmacies and community-based distribution systems initiated by the Gambia Family Planning Association, as well as in Government clinics and in the then five major health-care centres. The contraceptive prevalence rate is very low in the Gambia; only 8 per cent of the women of reproductive age use modern methods of family planning and 1 per cent using traditional methods [7]. Low levels of contraceptive prevalence can be attributed to several factors. One of the most important is that contraceptive services are not provided to women under the age of 21 years, even though 42 per cent of the Gambian population is under age 15 and the median age is 18.8 years [7]. Unmarried mothers must obtain parental consent in order to receive family planning services. Other factors contributing to low rates include illiteracy, traditional practices, and the low status of women; as well as inadequate and under-trained medical personnel, and low morale among family planning workers, poor communication and insufficient funding.

The effective use of contraceptives saves women's lives and preserves their health by protecting them from the health risks of frequent childbirth and unsafe abortion. The low contraceptive rate has resulted to a high fertility rate of 5.6 births per woman [7]. Moreover, the total unmet need for Family Planning in The Gambia is one in every four currently married women of which $20 \%$ have an unmet need for spacing, and 5\% have an unmet need for limiting births [7]. Furthermore, the country registers a maternal mortality rate of 433 per 100,000 live births and about $25 \%$ of all these deaths are due to hemorrhage, [7]. This could have been prevented through effective use of contraceptive methods such as the Levonorgestrel implant (LI). Despite the high level of knowledge of contraceptive methods at $96 \%$ of currently married women and $98.2 \%$ of currently married men knowing at least one method, and the knowledge level for implants in particular at $30.2 \%$ for women and $19.0 \%$ for men, contraceptive use is declining in The Gambia according to data from the Gambia Demographic and Health Survey [7]. The proportion of married women who reported current use of any contraceptive method reduced from 13\% in 2010 to $9 \%$ in 2013 [7]. The reason for low contraceptive use may be attributed to religious and cultural factors, use of traditional methods, side effects, health concerns, desire to get pregnant, convenience of method, coital reasons, lack of access and excessive costs [7].

The perception and acceptance of implants among users is not well documented in the Gambia despite established knowledge of availability at little or no cost in most health facilities. The perceptions of clients may encourage or discourage couples from using implants and other family planning methods. Therefore, understanding client's perceptions of implants will help to improve acceptance, thus reducing unintended pregnancies, induced abortion, short birth intervals, fertility rates and maternal mortality and morbidity in the country.

\section{Significance of the Study}

In 2010, the United Nations General Assembly, noted that gaps still exist in the implementation of different areas of the International Conference on Population and Development (ICPD) programme of action, decided to extend the programme and the key actions for its further implementation beyond 2014, in order to fully meet the programme's goals and objectives. Providing quality family planning services to ensure desired and intended fertility, including prevention of mis-timed and unwanted pregnancies is one of the strategic foci of the national reproductive health policy in the Gambia [8]. This is one of the factors that inspired this study in order to help in the reduction of maternal morbidity and mortality in the area of promoting and encouraging the use of Levonorgestrel implants which is a form of contraception recommended for under- resourced nations, especially The Gambia. Furthermore, findings of the study will help to inform policy makers on the perceptions and acceptance/satisfaction of implant users and to strengthen IEC and hence to improve informed choices about the use of implants. It will also contribute to the knowledge gap in the literature related to the subject as research has shown that studies related to the perceptions and acceptance of implants and their influence on uptake and use are yet to be fully documented, therefore making this particular study timely. This study therefore explores the perceptions and acceptance of such implants among FP clients with a view to strengthening family planning method uptake.

\section{Materials \& Method}

\section{Design of the study}

A phenomenological qualitative study design was employed for this study. This design was adopted to describe the views, opinions, life experiences and perspectives of the study participants concerning the use of levonorgestrel implants.

\section{Study setting}

The study was intended to cover four health facilities within the region where it targeted 60 Levonorgestrel implant users but ended up in two facilities because of difficulty in gathering study participants. However, the study was conducted in two health facilities around the Greater Banjul Area, namely Bundung Maternity and Child Health Hospital (formerly Jammeh Foundation for Peace Hospital) and Poly Clinic. The ultimate purpose of choosing these facilities is due to their proximity and the high turnout of patients seen on daily basis. Bundung Maternity and Child Health Hospital is located in the centre of the town and serves the inhabitants of Bundung and its surroundings.

Poly Clinic is located in Banjul under the supervision and management of the main teaching hospital, Edward Francis Teaching Hospital (EFSTH). It offers services such as general outpatient services with different units such as Psychiatric, Dermatology, Leprosy/TB, medical clinic, Ear Nose and Throat (ENT), Pharmacy, Laboratory services, Ophthalmic as well as Reproductive and Child Health services. The family Planning clinic operates on a daily basis with an average of twenty patients seen daily, among which the implant is the second highest among the different methods available. 
Citation: Dampha I, Jasseh M, Sey-Sawo J (2018) Perceptions and Acceptance of Levonorgestrel implants among Family Planning Clients within greater Banjul Area, The Gambia. Int J Nurs Clin Pract 5: 293. doi: https://doi.org/10.15344/2394-4978/2018/293

Page 3 of 7

\section{Sample size and technique}

The total number of study participants was twelve. This was purposively selected in each facility among Levonorgestrel Implant users. Data collection took a course of two days through audio recording and field notes taking, with each discussion lasting between 45 to 48 minutes. All the necessary materials needed for the procedure were gathered to aid in the process and a research assistant was trained and invited during the discussions. The focus group discussion guide was used to facilitate the discussions and each participant was given a number for easy identification. The group in Bundung consisted of seven married women in which one opted out during the discussion. The data collected from the participants were later transcribed in English Language for easy analysis.

\section{Data collection tool}

The instrument used in this study was adopted from the Gambia Demographic and Health Survey [9] on Family Planning and Contraceptive which was guided by the study objectives. A focus Group Discussion guide addressed women's perceptions and acceptance. It was divided into three main sections; (a) Sociodemographic data, (b) Perceptions, and (c) Acceptance of levonorgestrel implants among the participants.

\section{Inclusion and exclusion criteria}

1. Levonorgestrel implant users between the ages of 20-49 years;

2. Levonorgestrel Implant users with one year experience or more;

3. Clients that were willing to participate in the study;

4. Clients that speak and understand the Mandinka and/or Wollof languages.

While exclusion was based on:

1. Acceptors with less than a year's experience;

2. Women less than 20 years or more than 49 years old;

3. Clients not using Levonorgestrel implants;

4. Male Family Planning clients;

5. Clients that are dump and deaf.

\section{Data Analysis}

Qualitative data analysis method used for the study was the Editing Analysis Style where, the data were interpreted in search of meaningful segments and units. Once these segments were identified and reviewed, a categorization scheme was developed with corresponding codes that were used to sort and organize the data. Patterns and structures were then searched to connect the thematic categories. The first phase following data collection was done by listening to the audios from the FGDs, manual transcription, and reading and re-reading the transcripts, following which interpretation was done to deduce meaning from the data collected. The data were analyzed using themes and categorizing the responses of the participants under each theme with verbatim quotes used wherever necessary. Thematic analysis was finally done considering the objectives of the study which finally portrayed the findings.

\section{Ethical considerations}

A research proposal was written and submitted to the School of Medicine and Allied Health Sciences Research Publication and Scientific Committee for approval. Permission to conduct the study was also sought from the Joint Gambia Government/ MRC Ethics committee. Written consent was also sought from the various health facilities that the study was conducted following which approval was also given to embark on data collection. Both written and verbal consent was sought from the study participants who were also assured of the highest degree of confidentiality and were informed that they could opt out during the exercise anytime they wished to do so. All the data that were collected was effectively managed by safely keeping them in a locker to ensure confidentiality.

\section{Findings and Discussion}

\section{Findings}

\section{Sociodemographic characteristics of participants}

The sample consisted of twelve participants. Majority of the women were between the ages of 30-39 ( $\mathrm{SD} \pm 5.35$ ) ranging from 25 to 45 years with a mean age of 32.75 years. More than half of the study participants had between $1-4$ children $(n=7,58.33)$, with a mean parity of 3.75 ( $\mathrm{SD} \pm 2.48)$. Almost all of them were Muslims ( $\mathrm{n}=11,91.66 \%)$.All of them received some form of education with the highest level being secondary (Conventional) $(\mathrm{n}=6,50 \%)$. Majority were housewives $(\mathrm{n}=$ $6,50 \%)$, married $(n=11,91.66 \%)$. See table 1 for details.

\section{Participants perceptions on Levonorgestrel implants}

The findings showed that the following five themes emerged from the qualitative data on perceptions. The women perceived the Levonorgestrel implants differently such as efficacy, husband's approval or spousal consent, service provider's attitude, undesired effects, myths and misconceptions.

\section{Theme 1: Efficacy}

The study finding showed that women emphasized the effectiveness and efficacy of the implants as a family planning method when compared to other contraceptives, because you have sex with your husband many times without getting pregnant. Below is a verbatim excerpt of some of the participants;

"The reason why I choose the implant is because........... and I did not see any complications in it and am also not pregnant and all the people I know that fix the implant have not been pregnant too, so it's a good method". (FGD, BMCHH, Participant 1).

"Yes, the reason why I came to join is for me not to have a child early. I don't have a child, don't have a husband and I don't want to be pregnant, so that's what am up to presently". (FGD, PC, participant 7).

\section{Theme 2: Service provider's attitude}

All the participants reported favorably about their overall experience towards service providers at the family planning clinic. All participants found that providers were patient, spoke in a friendly way, listened well, and were generally warm and welcoming. Below is a verbatim quote from some of the participants. 
Citation: Dampha I, Jasseh M, Sey-Sawo J (2018) Perceptions and Acceptance of Levonorgestrel implants among Family Planning Clients within greater Banjul Area, The Gambia. Int J Nurs Clin Pract 5: 293. doi: https://doi.org/10.15344/2394-4978/2018/293

Page 4 of 7

"Yes its true nurses have a lot of patience. They are really patient when they are fixing it for you, they keep chatting with you, you will not even be conscious of what they are doing when they are fixing it for you. They even keep smiling at you. They direct you during the procedure until they are done and you will not even feel any discomfort" (FGD PC, Participant 3).

"For me when I came to insert it I was welcomed and they have patience too because they quickly inserted it with patience ......" (FGD, $\mathrm{BMCHH}$, participant 4).

\section{Theme 3: Husband /Spousal approval}

Findings reveal that male partner decisions positively influence women contraceptive choice particularly the Levonorgestrel Implant as highlighted by the following study participants;

"Family planning is very good because it helps in spacing and the time I was seeking for the services. I asked my husband and he advised me to join. It helps in spacing". (FGD, BMCHH, Participant 3).

Yes it's true when you are joining Family Planning it's important to ask your husband whether you should join or not. When he consents to it you join and when he denies you shouldn't because he is your authority ..... (FGD, PC, Participant 1).

\section{Theme 4: Undesired effects}

Disruption of menstruation was one of the major complaints revealed by the study participants however; they were still satisfied with the method as stated below by some of them.
"What it does to me is sometimes the menses can sit for two months come or three months it will not come or otherwise when it comes I menstruate for ten days or twenty days it will not stop, and it itches too however am still satisfied with it."(FGD, PC, Participant 6).

"Many people that remove it is because of too much blood. I saw a lot of women when I came here on Friday wanting to remove it reported such side effects but I personally did not have any complications with it" (FGD, BMCHH, Participant 1).

\section{Theme 5: Myths and misconceptions}

Majority expressed various rumors associated with the use of implants such as affecting physical wellbeing, weight gain, Infertility, shifting of the implant in the body, causing cancer etc. Following is a verbatim quote from some of the participants;

"People talk a lot. People say it's not good if you don't remove it, it can lead to infertility thereby causing other problems. So many things are being said. It makes you gain weight... ". (FGD, BMCHH, Participant 4).

"It gets lost in your body, causing cancer and etc...." (FGD, PC, Participant 3).

Participants views about Levonorgestrel Implant acceptance (satisfaction)

The theme that emerged from this data was satisfaction because it doesn't require frequent hospital visits and there is nothing like being

\begin{tabular}{|c|c|c|c|c|c|c|c|c|}
\hline Variable & Freq $(n)$ & $\%$ & Range & Mean & $\mathrm{SD} \pm$ & Variable & Freq $(\mathrm{n})$ & $\%$ \\
\hline Age (yrs) & & & & & & Marital Status & & \\
\hline $20-29$ & 3 & 25.0 & & & & Married & 11 & 91.7 \\
\hline $30-39$ & 8 & 66.7 & $25-45$ & 32.75 & 5.35 & Unmarried & 1 & 8.3 \\
\hline $40-49$ & 1 & 8.3 & & & & Widow & 0 & 0.0 \\
\hline Parity & & & & & & Ethnicity & & \\
\hline 0 & 1 & 8.3 & & & & Jola & 6 & 50.0 \\
\hline $1-4$ & 7 & 58.3 & & & & Mandinka & 3 & 25.0 \\
\hline $5-8$ & 3 & 25.0 & & & & Wollof & 1 & 8.3 \\
\hline \multirow[t]{2}{*}{$9 \leq$} & 1 & 8.3 & $1-9$ & 3.75 & 2.48 & Fula & 2 & 16.7 \\
\hline & & & & & & Other & 0 & 0.0 \\
\hline Religion & & & & & & Education & & \\
\hline Islam & 11 & 91.7 & & & & Yes & 12 & 100.0 \\
\hline Christianity & 1 & 8.3 & & & & No & 0 & 0.0 \\
\hline Educational Type & & & & & & Occupation & & \\
\hline Madrassa & 5 & 41.7 & & & & Civil Servant & 3 & 25.0 \\
\hline \multirow[t]{2}{*}{ Conventional } & 7 & 58.3 & & & & Business & 3 & 25.0 \\
\hline & & & & & & Housewives & 6 & 50.0 \\
\hline \multicolumn{9}{|l|}{ Educational Level } \\
\hline Primary & 4 & 33.3 & & & & & & \\
\hline Secondary & 6 & 50.0 & & & & & & \\
\hline Tertiary & 1 & 8.3 & & & & & & \\
\hline Not stated & 1 & 8.3 & & & & & & \\
\hline
\end{tabular}


Citation: Dampha I, Jasseh M, Sey-Sawo J (2018) Perceptions and Acceptance of Levonorgestrel implants among Family Planning Clients within greater Banjul Area, The Gambia. Int J Nurs Clin Pract 5: 293. doi: https://doi.org/10.15344/2394-4978/2018/293

forgetful about usage. Almost all the participants reported that they were satisfied with the method because of its convenience.

\section{Theme 6: Satisfaction}

"The fix is better that is why I choose it because I have used the pills before and I sometimes forget to take it that is why I choose this method. I've used both the pill and the injectable and am now ending up with the implant, and I have realized that this is the best method because there is nothing like forgetting either to take it or missing your appointment so that is the reason why I choose it"(FGD, BMCHH, participant 5 ).

"The benefits I have seen in this fix is that you can take care of yourself and you can have time because your births being so close to each other you cannot have time to take care of yourself or your kids, but you see when you fix it you can take care of your kids and take care of yourself. That's the benefit I have seen in it and am definitely satisfied with it "(FGD, PC,Participant 1).

\section{Discussion}

\section{Sociodemographic characteristics of participants}

The findings of the study revealed that the majority of the participants were within the ages $30-39$ years $(n=8 ; 66.7 \%)$ with a mean age of 32.75 years, had between 1-4 Children ( $n=7 ; 58.3 \%)$ and were married $(n=11 ; 91.7 \%)$. These findings are consistent to a study conducted in Nigeria where the majority were in the same age bracket, had less than four children and married [10]. These similarities could be attributed to the fact that the Gambia and Nigeria share the same geographical location, therefore they share the same background characteristics in their population. Furthermore, participant's religious status, educational level and occupation were congruent with that of Anyawu and Alida where these characteristics form the majority [11]. Attaining an educational level especially at secondary level is associated with decision making power of women to use contraceptives $[12,6]$. This finding is also consistent with Teferra and Wondifraw which showed the importance of education to use long acting contraceptives (LACs) [13]. Women with secondary and higher level of education were more likely to use LACs than uneducated women. Moreover, educated women may be able to make more informed decision regarding their own health.

\section{Participants perceptions on Levonorgestrel Implants}

\section{Efficacy}

Participants of this study appreciated the efficacy of the Jadelle as a family planning method in preventing pregnancy. This result is similar to the findings of who found out that women perceived the implant as a very effective contraceptive in the prevention of pregnancy when compared to other methods of contraception by Power, French and Cowan [14]. Similar findings were related by who concluded that the implant was an effective method of long term reversible contraception by Aisien [15].

\section{Service Provider's Attitude}

Majority of the participants reported favorably about their overall experience with service provider attitude at the family planning clinic. This was congruent with a report in Rwanda where most women found that providers spoke in a friendly way, listened well, and responded to all their questions [16]. This could be attributed to the fact that almost all of them were counselled by the providers which was well appreciated by the women.

\section{Husband /spousal approval}

Almost all the study participants concluded that spousal consent and approval are key when seeking the services of Levonorgestrel Implants. This finding is similar to a study conducted by Anguzu et al. entitled Knowledge and attitude towards use of long acting reversible contraception among women of reproductive age in Kampala District, Uganda, which also concluded that nearly half of the study participants reported that their male partners should decide on the contraceptive to use suggesting that sociocultural perceptions play an important part in contraceptive choice made [17]. A similar study in Kenya and Ethiopia also found that partner approval and husband support influence use of FP services and contraceptives respectively $[18,19]$. This study also has similar findings on partner's decision on spouse's choice of contraception. Partner decision was associated with women's contraceptive use similar to findings in Ghana, Nigeria and Rwanda where partner approval, partner support or partner objective towards contraceptive choice influenced contraception [20-22]. Therefore spousal consent needs to be sought before service is offered to Levonorgestrel Implant users. This can be surrounded by so many factors such as the bounds of religion and culture where the husband has the authority to decide on the number and spacing of children a family will have. Seeking spousal consent can also promote continuity and effectiveness of service where a male partner allows his spouse to use the service.

\section{Undesired effects}

Most of the participants complained of undesired effects like disruption of menstruation where they had either amenorrhea, spotting or heavy bleeding episodes. This is consistent with a study in Bangladesh that found a greater proportion of the women had experienced menstrual disorder [23]. This included prolonged or heavy bleeding as well as spotting. The changes in the menstrual pattern do not affect the women's health absolutely but irregular and, therefore, unpredictable or prolonged bleeding is significant because women need to make arrangements for their sanitary protection. Furthermore, irregular and prolonged bleeding affects both conjugal relations and religious practice. During menstruation, women are considered spiritually impure. Thus, irregular and prolonged bleeding ultimately creates psychological problems among the users. Similar findings were also reported by Babalola and Neetu where participants perceived the method to cause amenorrhea; nonetheless, the study participants demonstrated awareness about the method. However, it was perceived to be more effective than short-acting methods and even than the Intra Uterine Device (IUD) [24].

The similarities in both studies could be attributed to the fact that the two countries are Islamic countries which observe there religious obligations by performing the five daily prayers which a menstruating woman cannot perform because she is regarded as impure during that period. Therefore appropriate measures should be accorded to help women deal with such cases like offering them appropriate counselling and good therapy to counteract some of these undesired effects. In the contrary, another study by Aisien revealed that the implant produces minimal side effects. This is in contrary to this study where women reported the occurrence of undesired effects despite its high acceptance level [16]. 
Citation: Dampha I, Jasseh M, Sey-Sawo J (2018) Perceptions and Acceptance of Levonorgestrel implants among Family Planning Clients within greater Banjul Area, The Gambia. Int J Nurs Clin Pract 5: 293. doi: https://doi.org/10.15344/2394-4978/2018/293

Page 6 of 7

\section{Myths and Misconceptions}

In this study, majority of the women expressed rumours and misconceptions about Implants. This is similar to findings in Adigat Town in Ethiopia, where more than half were married women had myths towards the practice of LAPMs, such as excessive bleeding, infertility, or cancer [24]. Misinformation about modern contraceptive methods is still present. Furthermore, shifting or expulsions of the Implants, getting lost in the body via the bloodstream were cited by a number of participants [24]. The similarities in the two studies could be attributed to the fact that the same study designs were used and both countries are third world countries sharing the same cultural beliefs.

\section{Satisfaction}

In this study, women also expressed satisfaction related to the implant because of its convenience since it doesn't require frequent hospital visits and there is nothing like being forgetful about usage. Another study in Indonesia also found that women were more satisfied with implant use than the other methods [22]. In addition, findings revealed by Mutihir stated that women accepted the new method because it appeared to have a good continuation rate and therefore a promising long term sub-dermal contraceptive method amongst women [25]. In contrast, to other studies which stated that many women discontinued implants because they wanted to become pregnant and side effects were the primary reasons for early removal in most studies [26].

\section{Conclusions and Implications}

The use of Implants for family planning depends on clients' perceptions. Therefore knowing client's perception will better inform policy and health care providers in the pattern of uptake and quality services in family planning especially Levonorgestrel Implants, thus contributing towards the reduction of unintended pregnancies, induced abortions, short birth intervals, fertility rates and maternal morbidity and mortality in the country.

\section{Implications of findings to nursing}

Providing quality family planning services to ensure desired and intended fertility, including prevention of mis-timed and unwanted pregnancies is one of the strategic foci of the national reproductive health policy in the Gambia. Therefore, the study will contribute to knowledge development especially in the area of Levonorgestrel Implant as well as bridge the gap in the literature where it can serve as a reference point for evidence. Moreover the study design used can be replicated in other regions in the country and the outside world.

The Levonorgestrel implant was introduced in The Gambia in 2011; however no documented study has been conducted to better understand the perceptions and acceptance level among users. Therefore, understanding client's perceptions on Implants will help increase uptake, thus reducing unintended pregnancies, induced abortion, short birth intervals, and high fertility rates and also curbing the high maternal morbidity and mortality in the country. Furthermore, the study findings will help to inform policy makers on the perception and acceptance/satisfaction of implant users and to strengthen IEC and hence to improve informed choices about the use of implants.

\section{Competing Interests}

I hereby declare that there is no competing interests in this article as the production of all the work was totally facilitated and financed by the author as a thesis requirement.

\section{Author Contribution's}

Mrs Isatou Dampha (MSc, BSc, and HND, RN) is the main author who has made substantial contributions to the conception and design, acquisition of data, analysis and interpretation of data and drafting the manuscript.

Mrs Jainaba Sey-Sawo (PhD Student, MSc, BSc, and FWACN, RN) was involved in revising it critically on important intellectual contents.

Dr Momodou Jasseh $(\mathrm{PhD})$ was involved in revising it critically on important intellectual contents.

\section{Acknowledgements}

I praise the almighty God for his loving kindness and grace which accompanied me during the entire research period.

To my supervisors Mrs Jainaba Sey-Sawo (Lecturer and PHd Student) and Dr Momodou Jassey of Medical Research Council, The Gambia.

\section{References}

1. Quinn H, Le May A (2008) Introducing the Contraceptive Sino Implant II (Zarin) in Sierra Leone. Marie Stopes International, London.

2. Elias B, Hailemariam T (2015) Implants Contraceptive Utilization and Factors Associated Among Married Women in the Reproductive Age Group (18- 49 Year) in Southern Ethiopia. Journal of Women's Health Care 4: 281.

3. Ngo TD, Nuccio O, Pereira SK, Footman K, Reiss K, et al. (2016) Evaluating a LARC Expansion Program in 14 Sub-Saharan African Countries: A Service Delivery Model for Meeting FP2020 Goals. Matern Child Health J 21: 17341743.

4. Mitchel MJ, Thistle P (2004) Acceptability of levonorgestrel subdermal implants versus tubal ligation for long-term contraception in a rural population of Zimbabwe. Contraception 70: 483-486.

5. Masters T, Everett S (2005) Intrauterine and barrier contraception (a practica review of recent developments). Current Obstetrics \& Gynaecology 15: 31 37

6. Kamara BO Rodriguez $R$ Chorwe-Sungani G Chimwaza A (2015) Perceptions of Couples Who Use Jadelle Implant in Blantyre District, Malawi. Open Journal of Nursing 5: 994-1003.

7. The Gambia Demographic and Health Survey (2013),The Gambia Bureau of Statistics and ICF

8. National reproductive health policy document (2007-2014) The Gambia

9. The Gambia Bureau of Statistics (GBOS) and ICF International (2014) The Gambia Demographic and Health.

10. Irinyenikan $T$ (2016) Perception of Women about Implanon as a Contraceptive Method in Akure Western Nigeria. British Journal of Medicine and Medical Research 12: 1-6.

11. Anyanwu M, Alida BWN (2017) Uptake of long-acting reversible contraceptive devices in Western region of the Gambia. Afr Health Sci 17: 409-417.

12. Bogale B, Wondafrash M, Tilahun T, Girma E (2011) Married Women'S Decision Making Power on Modern Contraceptive Use in Urban and Rural Southern Ethiopia. BMC Public Health 11: 342.

13. Teferra ST, Wondifraw AA (2015) Determinants of Long Acting Contraceptive Use among Reproductive Age Women. Science journal of public health 3 : 143-149. 
Citation: Dampha I, Jasseh M, Sey-Sawo J (2018) Perceptions and Acceptance of Levonorgestrel implants among Family Planning Clients within greater Banjul Area, The Gambia. Int J Nurs Clin Pract 5: 293. doi: https://doi.org/10.15344/2394-4978/2018/293

14. Power J, French R, Cowan FM (2007) Subdermal Implantable Contraceptives versus other Forms of Reversible Contraceptives or other Implants as Effective Methods for Preventing Pregnancy (Review).

15. Aisien AO (2007) Contraception with Levonorgestrel Subdermal Implants (NorplantR) in Benin-City, Nigeria: A 12-year Review. African Journal of Reproductive Health 11: 90.

16. Family Health International (2013) Examining the Infl uence of Providers on Contraceptive Uptake in Rwanda. Banjul, The Gambia, and Rockville, Maryland, USA: GBOS and ICF International.

17. Anguzu $R$, Tweheyo $R$, Sekandi JN, Zalwango $V$, Muhumuza $C$, et al (2014) Knowledge and attitudes towards use of long acting reversible contraceptives among women of reproductive age in Lubaga division, Kampala district, Uganda. BMC Research Notes 7: 153.

18. Okech TC, Wawire DW, Mburu KD (2011) Contraceptive use among women of Reproductive age in Kenya's City Slums. International Journal of Business and Social Sciences.

19. Berhane A, Biadgilign S, Amberbir A, Morankar S, Berhane A (2011) Men's knowledge and spousal communication about modern family planning methods in Ethiopia. Afr J Reprod Health 15: 24-32.

20. Chigbu B, Onwere S, Aluka C, Kamanu C, Okoro O, et al. (2010) Contraceptive choices of women in rural Southeastern Nigeria. Niger J Clin Pract 13: 11-15.

21. Brunie A, Tolley EE, Ngabo F, Wesson J, Chen M, et al. (2013) Getting to 70\%: Barriers to modern contraceptive use for women in Rwanda. Int J Gynaecol Obstet 123: e11-e15.

22. Huda FA, Chowdhuri S, Sirajuddin MF (2014) Importance of appropriate counseling in reducing early discontinuation of Norplant in a Northern District in Bangladesh. J Health Popul Nutr 32: 142-148.

23. Babalola S, Neetu J (2012) Factors underlying the use of long-acting and permanent family planning methods in Nigeria: a qualitative study.

24. Gebremariam A, Addissie A (2014) Knowledge and Perception on Long Acting and Permanent Contraceptive Methods in Adigrat Town, Tigray, Northern Ethiopia: A Qualitative Study. International Journal of Family Medicine.

25. Mutihir TJ, Daru PH (2008) Implanon Sub-dermal implants: A10 month review of acceptability in Jos, North- Central Nigeria. Nigeria Journal of Clinical practice, 11: 320-323.

26. Meckstroth RK, Darney PD (2001) Implantable Contraception. Semin Reprod Med 19: 339-354. 